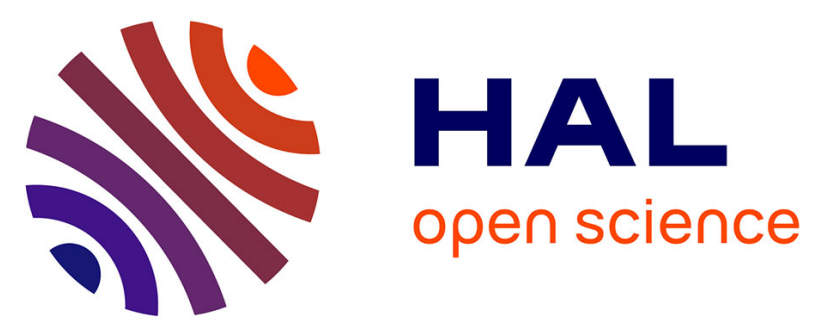

\title{
The multiple roles of sustainability indicators in informational governance: between intended use and unanticipated influence
}

\author{
Markku Lehtonen, Léa Sébastien, Tom Bauler
}

\section{To cite this version:}

Markku Lehtonen, Léa Sébastien, Tom Bauler. The multiple roles of sustainability indicators in informational governance: between intended use and unanticipated influence. Current Opinion in Environmental Sustainability, 2016, 18, pp.1 - 9. 10.1016/j.cosust.2015.05.009 . hal-01511021

\section{HAL Id: hal-01511021 \\ https://hal-univ-tlse2.archives-ouvertes.fr/hal-01511021}

Submitted on 20 Apr 2017

HAL is a multi-disciplinary open access archive for the deposit and dissemination of scientific research documents, whether they are published or not. The documents may come from teaching and research institutions in France or abroad, or from public or private research centers.
L'archive ouverte pluridisciplinaire HAL, est destinée au dépôt et à la diffusion de documents scientifiques de niveau recherche, publiés ou non, émanant des établissements d'enseignement et de recherche français ou étrangers, des laboratoires publics ou privés. 


\section{The multiple roles of sustainability indicators in informational governance: between intended use and unanticipated influence Markku Lehtonen ${ }^{1,2}$, Léa Sébastien ${ }^{3}$ and Tom Bauler ${ }^{4}$}

Indicators of sustainable development (SDIs), societal progress and wellbeing are perceived as informational tools vital for sustainability governance. The literature has thus far overwhelmingly concentrated on improving the technical quality of the indicators, while the role of these indicators in policy processes remains under-researched. Drawing on literature concerning policy evaluation and assessments - as well as the emerging literature on the interplay between indicators and policy - this article identifies a number of issues central for the role of SDIs in governance processes. It draws attention to the multiple indirect pathways through which these indicators exert their influence, highlighting the conceptual and political roles of SDIs. The conclusions outline a number of trade-offs and ambiguities inherent in the use and development of indicators.

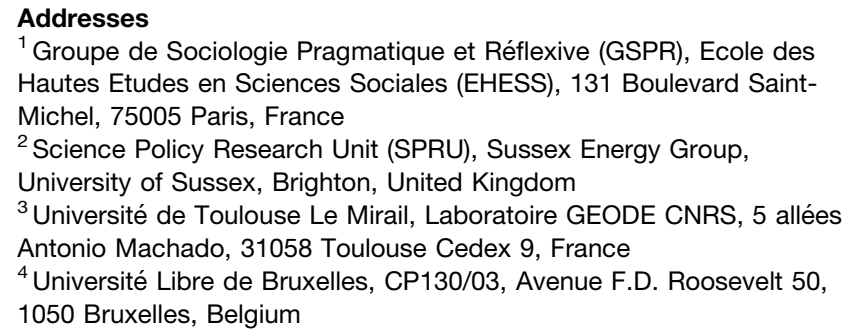

${ }^{1}$ Groupe de Sociologie Pragmatique et Réflexive (GSPR), Ecole des Hautes Etudes en Sciences Sociales (EHESS), 131 Boulevard SaintMichel, 75005 Paris, France

${ }^{2}$ Science Policy Research Unit (SPRU), Sussex Energy Group, University of Sussex, Brighton, United Kingdom

${ }^{3}$ Université de Toulouse Le Mirail, Laboratoire GEODE CNRS, 5 allées Antonio Machado, 31058 Toulouse Cedex 9, France

${ }^{4}$ Université Libre de Bruxelles, CP130/03, Avenue F.D. Roosevelt 50, 1050 Bruxelles, Belgium

Corresponding author: Lehtonen, Markku (m.lehtonen@sussex.ac.uk)

Current Opinion in Environmental Sustainability 2016, 18:1-9

This review comes from a themed issue on Sustainability governance and transformation

Edited by Bertrum MacDonald, Katrien Termeer, Paul Opdam and Katrine Soma

Received 16-1-2015; Revised 20-5-2015; Accepted 21-5-2015

http://dx.doi.org/10.1016/j.cosust.2015.05.009

1877-3435/C 2015 Elsevier Ltd. All rights reserved.

\section{Introduction}

Instigating rapid socio-technical transitions on a broad systemic level towards more sustainable development pathways is a fundamental challenge for environmental policy. From a conventional perspective of indicators as tools of management, in line with what Mol (2006, 506) has labelled 'informational managerialism', indicators are expected to rather unproblematically contribute to such transitions, by providing feedback on the effects of policies, identifying and describing unsustainable evolutions, co-constructing visions and evaluating pathways towards desired societal change. Such information is then expected to accelerate processes of transformation towards sustainability. In rather direct opposition to this rather naïvely optimistic view of the emancipatory and empowering capacity of indicators, alternative and highly critical readings have emerged, highlighting the potentially dysfunctional and roles of indicators in reinforcing the prevailing asymmetries of power - functions highly questionable from the point of view of democracy $\left[1,2^{\bullet \bullet}, 3,4,5\right]$.

Both academic literature and policy practice in the area of indicators in general and sustainable development indicators (SDIs) ${ }^{5}$ in particular has tended to focus on the need to improve the 'intrinsic' quality of indicators, hence assuming that the better the indicators, the more they will be used. ${ }^{6}$ This greater use is, in turn, believed to automatically generate stronger influence on policy, and thereby enhance sustainability. These assumptions are underpinned by a rational-positivist perception of policymaking, whereby information plays an instrumental role in directly feeding as inputs into policy processes. However, recent indicator research has increasingly called into question such an unproblematic role of information in policymaking, and instead drawn attention to the numerous indirect pathways through which indicators exert their influence. These indirect types of policy influence of SDI are overlooked within the still dominant linear model of policymaking [6,7], which considers indicators as neutral tools of governance. More often than directly informing decision-making, SDIs fulfil numerous performative functions, operating as classifications, and

\footnotetext{
${ }^{5}$ In this article, we use the terms "sustainable development indicators", "sustainability indicators", and "indicators of sustainable development" as synonyms, with the abbreviation SDI referring to all of the three.

${ }^{6}$ While articles published in journals such as Ecological Indicators and Social Indicators Research typically reflect search for scientifically more robust indicators, policy debates in various international arenas (e.g. OECD and Eurostat) tend to emphasise the need to produce more "policy relevant" indicators. In either case, the problem is perceived as one of insufficient quality of indicators.
} 
'reflecting back the conditions of their making in future manifestations in policy, or other forms of use' [8]. In doing so, indicators produce convergence - knowledge and the world itself become more and more aligned; they transform politics, as knowledge itself becomes a site of political action; and they entail contingency - by producing a host of unpredictable and uncontrollable effects [9]. Indicators therefore function as 'message carriers', helping to shape existing frameworks of thought, mental models, and serving as 'ammunition' used by the various participants in political debates [10]. Moreover, the conceptual functions often take place before the release of indicators, through the indicator development processes $\left[11^{\circ}, 12\right]$. And finally, empirical indicator research has questioned the assumption that 'use' automatically leads to 'influence' $\left[13,14^{\circ}\right]$. These findings largely echo literature on the role of evaluations, assessments, and scenarios - which has emphasised the importance of indirect forms of influence alongside the intended use of these types of information $[6,7,15,16]$.

In an attempt to clarify the potential roles of indicators in informational governance, this paper reviews recent literature, focusing in particular on the conceptual and political functions of sustainable development indicators at various governance levels - from the local to the international. We argue that research and practical work on indicators has thus far excessively focused on the instrumental functions of indicators as malleable governance 'tools', without due attention to the politico-institutional context, and that research work should instead seek to examine the operation of indicators within their broader context, including both the characteristics of indicator users and producers, and the political framework conditions shaping and being shaped by indicators. The focus in this paper is on the developed countries, and we do not specifically address the use of indicators in lessdeveloped societies. The paper is structured around three key topics, in order to clarify and better structure the discussion on the multiple roles of indicators: firstly typologies of intended and unanticipated functions of indicators, and the distinction between use and influence of indicators; secondly the various alternative approaches applied for analysing the indirect influence of indicators, notably the role of indicators as 'boundary objects' between science, society and policy; and thirdly the tradeoffs and dilemmas between the contrasting objectives and functions of indicators, and between the use and influence of indicators.

\section{Indicators: typologies and concepts}

Indicators can be defined as 'variables that summarise or otherwise simplify relevant information, make visible or perceptible phenomena of interest, and quantify, measure, and communicate relevant information' [17]. The underlying assumption is that of 'indication', that is, assessing a phenomenon that is not directly measurable (e.g. biodiversity or sustainability) through a limited set of measurable parameters $\left[18^{\bullet \bullet}\right]$. Unlike many other information types, notably data and statistics, indicators are based on an underlying conceptual framework, which anchors indicators in theory, establishes a logic to the selection of indicators, and provides the supporting technical definitions, metrics, and linkages, thereby situating an individual indicator within a broader network of information $[19,20]$. A distinction is sometimes made between quantitative and qualitative indicators, the latter being used in situations when the phenomenon in question is not measurable accurately, but can better be described (e.g. through grading based on qualitative findings). For the purposes of this paper, such distinction is not essential, since we argue that both quantitative and qualitative indicators are subject to the similar dynamics of production, use, and influence.

\section{Intended functions of indicators}

Indicators are expected to, and indeed do, serve multiple useful functions, such as communication and awarenessraising [21], monitoring and evaluation of performance, engaging stakeholders, supporting policy evaluation, providing early warning functions, political advocacy, control and accountability, transparency, and improving the quality of decisions. Further intended functions attributed to indicators include guidance to policy analysis and formation, improvement of government effectiveness, setting targets and establishment of standards, promotion of the idea of integrated action, and focusing of policy discussion. Indicators would then serve as 'signals' that enable or prescribe an action or management function, and condense information, helping policymakers to decide whether or not to act [19]. Whichever the primary objective, indicators are expected to simplify and facilitate communication by reducing ambiguity [22].

\section{Types and intended functions of environmental and sustainable development indicators}

Indicators can be classified into three broad categories descriptive, performance, and composite indicators each with its own preferred functions. Descriptive indicators are close to 'pure' data, without a specified intended use. Performance indicators place the observations on a normative scale, and thereby allow judging progress towards a norm (e.g. the evolution of GHG emissions in relation to an emission reduction target). Performance indicators are therefore designed to strengthen accountability, but can also serve other functions typically attributed to policy evaluation, in particular learning and policy improvement. Composite indicators (e.g. ecological footprint) draw attention to important policy issues, offer 'more rounded assessment of performance', and present the 'big picture' in a manner accessible to diverse audiences [23]. Rankings and league tables are increasingly popular types of composite indicators, which can signal quality of service and inform choice (including choices 
on resource allocation); or be used for performance benchmarking, accountability, and for the attribution of rewards [24]. Composite indicators of sustainable development can provide a shared conceptual framework, as basis for interpretation, analysis and practice - a kind of 'metatheoretical language' that enables comparison between theories, and may engender collective understanding of sustainability [25]. The strength of composites - their ability to simplify - also constitutes a weakness, since composites cannot identify causal relationships and alone provide a sufficient knowledge basis for specific policy decisions [26]. Composite indicators can therefore influence policy indirectly, by informing the public and the political debate about specific social objectives and policy trade-offs, making explicit underlying assumptions, challenging dominant models of measurement, helping the public to hold politicians to account, etc. $\left[27^{\circ}\right]$. Obviously, the three categories overlap, as for instance descriptive indicators typically constitute the essential building blocks of performance and composite indicators, and composites are frequently used also for performance measurement.

There has been a gradual shift in emphasis in the development of the various environmental and sustainable development indicators - from descriptive through performance to composite indicators. Many of the early environmental and sustainability indicators were descriptive, with the state of the environmental and natural resource indicators as perhaps the most typical example [20,28,29]. The rise of New Public Management and evidence-based policy as public sector 'megatrends', together with the demand for more 'policy relevant' indicators to complement the mere description of environmental conditions, stimulated the development of performance indicators, including sectoral performance indicator systems, league tables and rankings at various governance levels $\left[24,30^{\circ}, 31\right]$. Since the late 1990 s, environmental indicator work has become increasingly interdisciplinary and cross-sectoral [28], leading to the introduction of sustainable development indicators at various levels of governance, and the proliferation of various composite indicators of sustainability, including indicator development by international organisations such as the OECD, EEA, UN. The most recent trend has been the development of indicators of societal progress and wellbeing $\left[27^{\bullet}, 32,33^{\circ}\right]$.

None of the sets of sustainability indicators has emerged as hegemonic and universally applicable, not least because each set is aimed for use at a particular governance level. Some are designed to help a specific city, community or organisation to improve, and to 'empower' citizens, especially through participatory processes of indicator development (e.g. community-based monitoring) and by rendering the concept of sustainable development concrete [22]. Others, in turn, serve accountability, by facilitating comparisons across cities, organisations or countries [34]. The national-level composite indicators have their counterparts at the subnational and community levels, yet the functions of these indicators vary. Performance indicators, in turn, are typically designed to facilitate the control of the civil service by decision-makers at the relevant governance level - and to help the civil service to improve its day-to-day performance - for instance by measuring the degree to which environmental concerns are integrated into environmental policies (e.g. OECD and EU agri-environmental indicators, and environmental indicators for transport).

\section{Actual roles of SDIs}

The actual use, influence and broader consequences of indicators often diverge from their intended, 'legitimate' objectives and functions as foreseen by indicator designers and advocates. Three generic indicator roles can be identified. The instrumental role entails the use of indicators as direct input to specific decisions, in line with the linear rational-positivist model of policymaking, typically involving 'single-loop' learning, (i.e. learning that concerns the consequences of specific actions or policy options) [35]. In their conceptual role, indicators foster 'enlightenment', that is, 'the percolation of new information, ideas and perspectives into the arenas in which decisions are made' [15]. They do so by helping to shape the conceptual frameworks and mental models of actors, mostly through dialogue, public debate, and argumentation; by providing background information, and by creating shared understandings [36]. Conceptual role can be the consequence of the processes of indicator construction or of the indicators themselves. It would entail especially the more complex types of 'double and triple-loop' social learning in the spirit of Habermasian communicative rationality.

Finally, the political role also entails the more complex types of learning, indicators serving as 'ammunition', as part of attempts by policy actors to influence agendasetting and problem-definition, highlight neglected issues, or (de)stabilise and (de)legitimise prevailing frameworks of thought and actors. Indicators can then be used as a substitute for action and as a delaying tactic [37,38], or to legitimise predetermined positions and decisions already taken $[39,40] .^{7}$ Such political roles are often portrayed as 'misuse' of indicators for illegitimate purposes. Numerous measures have been suggested to minimise 'misuse', including information and education of the users and introduction of 'statistical health warnings' $\left[20,24,30^{\circ}, 26\right]$. However, the political role also encompasses necessary efforts to strengthen the legitimacy of

\footnotetext{
${ }^{7}$ Rapport and Hildén [41] include awareness-raising within legitimising use of indicators, as such use does not lead to immediate changes in policy. In our typology, awareness-raising is instead seen to fall within the category of conceptual functions of indicators.
} 
democratic decision-making, and advocacy for socially progressive objectives, including sustainable development [42]. Indicator construction can foster political effects, but arguably, it is usually the indicators themselves that play a political role, given that the indicator construction processes are usually sheltered from media and public exposure.

\section{Use of indicators does not automatically imply} influence - and influence does not always require use Most of the emerging research on the actual role of indicators in policymaking has focused on use, and has largely overlooked the ultimate consequences of indicator production and use. In contrast with the widespread assumption that the use of SDIs automatically enhances sustainability, we argue that the concepts of use and influence should be distinguished from each other. 'Use' can be defined as the handling (e.g. receiving, processing, communicating, and reporting) of indicators in a variety of policy venues, whereas influence denotes the ways in which dialogue and argumentation generated by indicators or indicator sets - or by the processes of designing and applying indicators $\left[11^{\circ}, 12\right]$-influence various elements of the policy chain. This way, indicators can foster social learning, networking, and greater focus and motivation among policy actors $\left[43^{\circ \bullet}\right]$. As Henry and Mark [44] note, in relation to evaluation use and influence, "the very concept of use connotes intentionality and awareness'. Even when not used actively by any policy actor, an indicator can influence policies and society through various indirect ways, mediated by complex pathways of processes and interim outcomes, and often with a considerable time lag. Moreover, the process whereby an indicator has been developed can condition indicator use - for instance, actors may consider that the process has poor legitimacy, and therefore reject the resulting indicators. Indicator influence can entail changes in the targeted policy, but also in broader processes in society, such as administrative structures or the operation of democratic institutions. Influence can imply new or reconfirmed decisions, actions, and shared understandings, enhanced networking, or changes in the legitimacy of a policy or a policy actor $[13,39,45]$. Figure 1 illustrates these relations between use and influence of indicators. The pathways between indicator design processes, indicators, indicator use, and indicator influence are complex and largely unpredictable. Hence, as the figure illustrates, the 'theoretical' assumed linear pathway from design process through use to influence on the targeted policy does not tell the whole story, and often does not even take place: an indicator may not always be used; use may fail to lead to influence; and the influence may not necessarily concern the targeted policy.

Crucially, indicators are not always used as intended, and the resulting influence may conflict with the sought objectives, or generate negative unintended effects $[4,24]$. Neither is use therefore always a 'good thing', nor is the
Figure 1

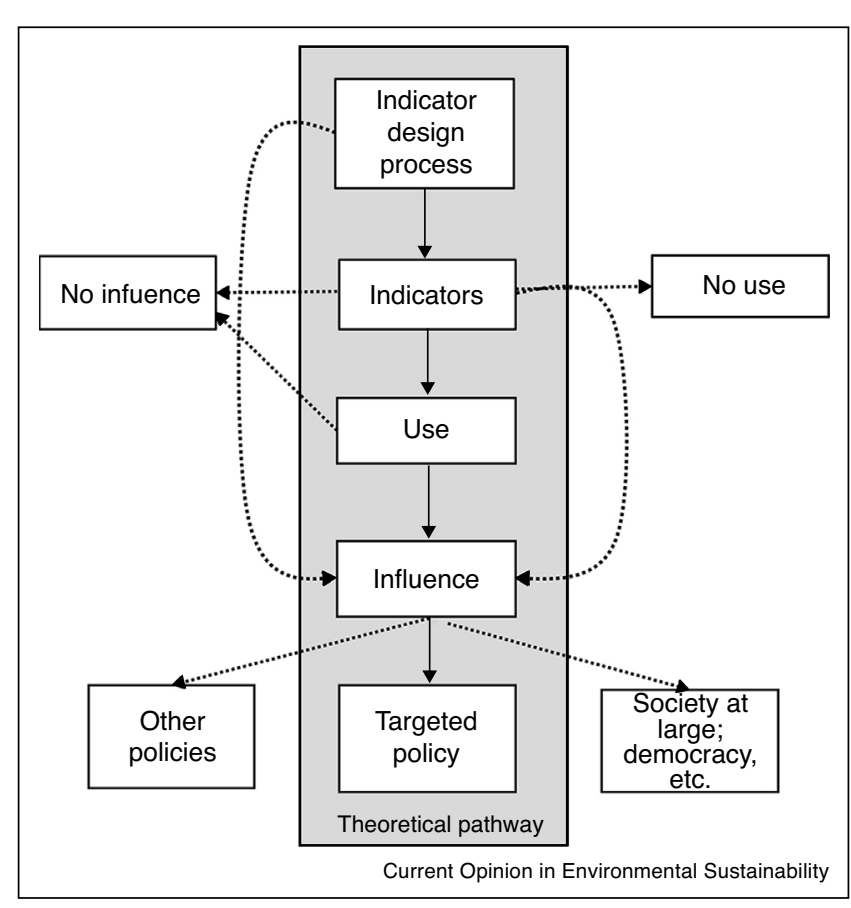

Relationships between the use and influence of indicators.

learning entailed in indicator work automatically desirable or undesirable per se. A typical example is what Hezri and Dovers [39] call 'political learning', whereby policy actors learn more sophisticated ways of advancing their policy ideas, possibly through manipulation and without greater concern for the general interest. Hence, the link between indicator use and influence is often tenuous and intractable - frequent use of indicators does not guarantee that they would be highly influential, whereas even indicators that are not actively used may nevertheless generate significant impacts through indirect pathways $\left[13,14^{\circ}\right]$. For example, many stakeholders considered the energy poverty headline indicator in the UK as highly deficient, but were quick to acknowledge that the inclusion of the fuel poverty indicator within the UK Energy Sector Indicators had been highly influential [13].

Table 1 summarises the types, intended functions, and actual roles of indicators.

\section{Indicators as boundary objects between science, society and policy}

The broader, indirect roles of indicators have been analysed from a number of different theoretical perspectives. These include scholarship on governmentality [ $2^{\bullet \bullet}$ ], government and management by numbers $\left[30^{\circ}, 46^{\circ} \cdot\right.$, and indicators as boundary objects capable of connecting science, policy, and society $\left[10,47^{\circ \bullet}\right]$. Indicators can operate as 'boundary objects' $\left[10,18^{\bullet \bullet}, 47^{\bullet \bullet}, 48\right]$, catering to both technocratic and deliberative ideals, by combining 
'hard facts' and modelling with collective reasoning and 'speculation'. When effective as boundary objects, indicators can mediate between different categories of policy actors, which Star $\left[47^{\circ}\right]$ calls 'social worlds'. The ability of indicators to connect science, policy and society [49 $\left.{ }^{\circ \bullet}\right]$ stems from their flexibility, ambiguity, and even vagueness, which allows them to have meaning in these distinct social worlds, but also be 'stable enough to travel back and forth between them' $\left[18^{\bullet \bullet}\right]$. A boundary object can therefore be tailored to local disciplinary work within a single community or a social world but it can nevertheless retain a common identity across settings $\left[18^{\bullet \bullet}\right]$. Boundary objects allow groups to work together without consensus, in a continuous process of tacking back and forth between the vague and the more tailor-made forms of the object $\left[47^{\bullet \bullet}\right]$.

Similarly, scholarship on governmentality [ $\left.2^{\circ \bullet}\right]$, and 'government/management by numbers' $\left[24,30^{\bullet}, 46^{\bullet \bullet}\right]$ highlights the systemic and indirect consequences of indicators, for instance the ways in which indicators trigger behaviours that conform to the demands of market society. ${ }^{8}$ These insights echo those from literature on informational governance, which illustrates ways in which informational requirements are thrust onto private and civil society actors, within a 'neo-liberal' logic that seeks to exercise regulatory control through market mechanisms [50]. Part of the influence hence operates through 'instrumentation', whereby indicators contribute to shaping problem formulations and solutions $\left[45,46^{\circ \bullet}\right] .^{9}$ The emancipatory potential of simplification - which makes problems accessible to non-experts - is therefore coupled with an opposite movement that legitimises the position of experts as the only ones capable of truly 'mastering' the numbers [45]. Integration of citizen-led and expert-led indicator development approaches has been suggested as a means of reducing the inherent tensions between experts and 'lay' people in indicator work [34]. However, as demonstrated for instance by scholars in urban studies, sociology, geography and urban planning, even participatory indicator exercises cannot guarantee that indicators foster socially desirable objectives. This is so in particular because of the embeddedness of indicator systems in the broader dynamics and trends in policymaking $\left[2^{\bullet \bullet}, 28\right]$, such as the evidence-based policy - arguably one of the current 'megatrends' of public sector management and governance. Again, this illustrates the distinction between use and influence: more indicator use may in fact lead to socially regressive outcomes.

\footnotetext{
${ }^{8}$ We use the term 'systemic' to cover the multiple impacts entailing complex and sometimes intractable causal relationships, whereby indicators affect the system within which they operate.

${ }^{9}$ Lascoumes and Le Galès [46] describe instrumentation of public policy as the whole of the problems generated by and involved in the choice and use of instruments (techniques, operational modes, policy instruments) that make it possible to materialize and operationalize government action.
}

These strands of scholarship have in common their criticism against the tendency of indicators to depoliticise, that is, to reduce value conflicts and normative debates to presumably neutral and commonly agreed numbers perceived as incontestable facts [51]. Sébastien and Bauler [32] have shown how composite indicators of sustainable development carry with them implicit worldviews, while the conflicts between alternative visions often remain implicit in, and hidden behind, debates on methodology. In examining the various systemic impacts, the abovementioned strands of literature draw attention to the conceptual and political functions of indicators.

\section{Trade-offs, dilemmas and paradoxes concerning indicator use and influence}

Adopting a systemic perspective, which emphasises the performative, indirect and largely uncontrollable impacts of indicators, draws attention to the numerous unavoidable trade-offs between various indicator roles and functions - trade-offs that stem from the nature of indicators as boundary objects.

Many of the tensions identified in the literature as inherent to indicator work stem from the absence of a linear connection between the use of indicators and their influence on policy. The multiple tensions include those between inductive and deductive approaches; the use of indicators either as inputs for policy design and implementation or as tools for monitoring and evaluation; international comparability and national/regional/local relevance; description and prescription; objectivity and normativity; aggregation and disaggregation; influence from the indicators themselves or from the processes through they are elaborated; and scientific quality versus practical usefulness $[21,52,53]$. The latter tension is often portrayed as a gap between indicator 'supply' and 'demand'; in this vein, recent analysis has suggested that the use of composite SDIs could be considered as 'selection pressure' that would help spur the development of better indicators and thereby presumably help bridge the gap [54].

While such tensions entail choices between alternative, as such desirable, objectives, especially the literature on performance measurement has highlighted the various 'dark sides' of indicators. This literature echoes some of the key tenets of informational governance, and its attention to the performative character of information, thereby calling into question the assumption that performance indicators would merely provide greater accountability, efficiency and citizen control over policymakers, as assumed by its most optimistic advocates. In the same vein as Mol (2006), who points to the perverse aspects of informational governance, relating to 'power, inequalities, and informational monopolies' - literature on performance measurement $\left[4,5,24,30^{\circ}, 31\right]$ has highlighted the downsides of performance indicators, which may be 
complex, opaque, and reductionist, hence hampering dialogue and deliberation, and legitimising or reinforcing prevailing power structures. These indicators can discourage responsibility, innovation, creativity and achievement; while fostering goal-shifting, 'gaming', dissimulation, and distortion of data. Surely, 'misuse' and 'manipulation' can stem from misunderstandings that result from ignorance of the sources, definitions and methods underlying the indicators, yet the perverse effects of performance indicators often result from their very nature; for instance, by suppressing the plurality of values and points of view, and by introducing a management rhetoric inappropriate in sectors with a 'non-managerial' tradition, performance indicators can contribute to a culture change entailing loss of public trust, and ultimately, even a risk of system collapse.

The above-mentioned trade-offs and perverse effects point to the more generic paradoxes and dilemmas involved in SDI work, especially in the increasingly widespread use and institutionalisation ${ }^{10}$ of indicators in for example reporting and assessment practice. While such phenomena can be seen as progress, the very policy 'success' also entails further risks and downsides. We highlight four of them in the following.

The 'paradox of conservatism'. ${ }^{11}$ The factors that enhance instrumental use - institutionalisation, consensus on data, policy and conceptual frameworks - often undermine the challenge function of indicators, (i.e. their capacity to destabilise prevailing practices, frameworks of thought, and 'hegemonic discourses') [1]. For instance, the paradigmatic consensus underpinning the GDP as a proxy measure for wellbeing has guaranteed its resistance against pervasive criticism [55]. A close fit between the 'repertoires' of indicator users and the repertoires embodied in the indicators facilitates direct use of the indicators, but if an indicator or an indicator set perfectly matches the conceptual frameworks of policy actors, it is unlikely to shake established mental models and institutions.

Empowerment versus control. Empowerment is frequently seen as the key objective of the numerous participatory processes of indicator development. Indicators can also empower citizens through simplification, and by helping citizens to hold policymakers accountable. Yet, indicators can likewise strengthen the position of the experts as the only ones truly capable of understanding and controlling their construction. Furthermore, many of the far-reaching systemic consequences from the application of indicator systems, together with their powerful framing effects, often mean that experts rather than

\footnotetext{
${ }^{10}$ By institutionalisation we mean the setting up of procedures and practices that ensure the continuing existence of an indicator and legitimise and formalise its methods and concepts [36].

${ }^{11} \mathrm{We}$ are grateful to Henrik Gudmundsson for having coined this term.
}

citizens are empowered. Indicators may disempower, regardless of how well-intentioned their designers and users may be. This is because indicator producers cannot fully control the ways in which indicators are used, and because the users are equally unable to predict and control the influence of indicators. Hence, the observation that 'appropriate indicators are determined by their intended use' [56] must be nuanced - there is frequently a discrepancy between the intended and the actual use and influence.

Opening up versus closing down. In the traditional rational-positivist perspective, indicators are expected to 'close down', enabling better management and control by providing robust, accurate, quantitative and unambiguous information for the purposes of political advocacy and day-to-day policymaking. However, as part of more reflexive and adaptive governance modes [57], indicators can help to 'open up' policy discourses and perspectives by highlighting uncertainties, trade-offs, and neglected issues in policymaking [58]. Such a 'challenge function' is inherent in alternative indicators of progress and wellbeing, for example. The tension between opening up and closing down manifests itself in the disagreements between 'science-driven' statisticians - often at the driving seat of indicator development, and typically reluctant to abandon what they consider a non-political, objective and science-based position [59] - and indicator users that call for policy-relevant rough-and-tumble indicators. Arguably, the balance is currently in favour of closing down $\left[60^{\circ}\right]$, as the involvement of politics in indicator work is widely seen as undesirable [13].

Consensus versus controversy. The dilemma between consensus and controversy is closely akin to that between closing down and opening up. Consensus on the underlying values, visions, worldviews and concepts is often seen as a precondition for the design of useful indicators. Likewise, indicator use is itself often seen as essentially a process of consensus-building. However, stirring controversy may appear as a more desirable objective when there is an excessive tendency towards 'closing down', unquestioned adherence to currently dominant frameworks of thought, and drive towards a premature consensus on the lowest common denominator. Furthermore, when knowledge is uncertain, and the policy situation is characterised by a diverse range of worldviews, reducing uncertainty and diversity in the hope of reaching consensus may be not only futile, but also undesirable. From this perspective - and in line with the idea that the virtue of boundary objects is their ability to facilitate collaboration amongst groups and individuals even in the absence of consensus - the challenge would be close to 'honest brokering' [61]: indicator work would not seek to reduce ambiguity, but instead highlight, clarify and explicate the disagreements, alternative perspectives, and uncertainties involved. 
Table 1

\begin{tabular}{|c|c|c|c|}
\hline Type of indicator & Descriptive & Performance & Composite \\
\hline $\begin{array}{l}\text { Intended indicator } \\
\text { functions }\end{array}$ & $\begin{array}{l}\text { - Communication } \\
\text { - Awareness-raising } \\
\text { - Transparency } \\
\text { - Target-setting } \\
\text { - Standard-setting }\end{array}$ & $\begin{array}{l}\text { - Monitoring and evaluation of performance } \\
\text { - Engaging stakeholders } \\
\text { - Support to policy evaluation } \\
\text { - Early warning } \\
\text { - Control and accountability } \\
\text { - Better decisions } \\
\text { - Guidance to policy analysis and formulation } \\
\text { - Better government effectiveness } \\
\text { - Political advocacy } \\
\text { - Target-setting } \\
\text { - Standard-setting } \\
\text { - Promotion of the idea of integrated action } \\
\text { - Focusing of discussion }\end{array}$ & $\begin{array}{l}\text { - Engaging stakeholders } \\
\text { - Control and accountability } \\
\text { - Political advocacy }\end{array}$ \\
\hline Actual indicator roles & & Instrumental Conceptual Political & \\
\hline
\end{tabular}

\section{Conclusions}

Our article has sought to illustrate how indicators of sustainable development can act as 'boundary objects' in informational governance, through mediating between the various 'social worlds'. More often than influencing policy directly and as intended by their producers and users, indicators produce their effects through various indirect pathways, unlike the still dominant - in its extreme versions rather utopian - view of indicators as direct inputs to policymaking would assume. When indicators play conceptual and political roles, they can have powerful and profound systemic impacts, such as when composite sustainability indicators shape worldviews and embody broader visions of society, or when the introduction of performance measurement systems contribute to the institutionalisation and reinforcement of general governance principles such as New Public Management and market liberalism. The fact that indicator influence repeatedly escapes the control of their producers and users also invalidates the simple assumption of 'greater use implies greater and better impacts' - a finding in line with lessons from informational governance. Depending on complex interplay between factors shaping indicator use including the quality attributes of the indicators themselves, the 'repertoires' of indicator users and producers, and the broader policy context - SDIs can either foster or prevent progress towards a more sustainable society. Indicators can be 'misused', but even when used 'correctly', they frequently produce undesirable outcomes: they can empower the already powerful, reinforce rather than challenge dominant framings, push for premature consensus on the lowest common denominator, impose upon local actors analytical frameworks suitable only at higher levels, etc. In contrast with the indicator utopianism, research on especially performance indicators has sometimes tended to highlight rather 'dystopic' views of indicators as nothing but tools of domination in the hands of the powerful.

The ambiguity between the utopian and dystopic visions of indicators are indeed typical of boundary work, and as such is clearly visible in numerous tensions, dilemmas and trade-offs faced in the use and production of indicators. These are particularly salient between different approaches to indicator production and use, and between different roles that indicators can play in policymaking. Indicators are not neutral 'tools' of governance, but instead potentially powerful 'actors' that produce often unpredictable impacts in complex governance settings. Further indicator research should therefore pay greater attention to the systemic and unanticipated impacts of indicators, and to the potential of indicators in helping to open up debates and perspectives, as part of efforts to foster reflexive and adaptive governance approaches. In particular, such efforts would require more analytical approaches that explicitly recognise the multiple, both enabling and constraining, dimensions of power, in an attempt to identify the contexts and mechanisms that shape the potential of indicators to serve progressive purposes. Finally, future attempts to bridge the gaps between the naïve optimism and overly deterministic negative visions of indicators could tackle a key issue of informational governance, which we have merely alluded to here, namely the tensions associated with democratic legitimacy in the interaction between the multiple levels of governance. While the development of new information and communication technologies in principle enables a host of new and more inclusive processes of indicator development, partly by blurring the boundaries and knowledge hierarchies between the 'producers' and 'users' of indicators, these methods have their limits and IC'T entails its own oppressive potential. Indeed, ICT developments tend to accentuate the risk that indicators developed through processes with limited legitimacy (e.g. by international organisations) come to play a decisive and often systemic role in national and local politics.

\section{References and recommended reading}

Papers of particular interest, published within the period of review, have been highlighted as:

- of special interest

-. of outstanding interest 
1. Driscoll Derickson K: Gendered, material, and partial knowledges: a feminist critique of neighborhood-level indicator systems. Environ Plan A 2009, 41:896-910.

2. Rydin $Y$ : Indicators as a governmental technology? The

-. lessons of community-based sustainability indicator projects. Environ Plan D Soc Space 2007, 25:610-624.

A major contribution to scholarship examining the role of indicators from a neo-foucauldian perspective of governmentality. Perceives local sustainability indicator work as a reflection of key elements in central - loca relations within contemporary governance.

3. Rydin Y, Holman N, Wolff E: Local sustainability indicators. Local Environ 2003, 8:581-589.

4. Perrin B: Effective use and misuse of performance measurement. Am J Eval 1998, 19:367-379.

5. Davies IC: Evaluation and performance management in government. Evaluation 1999, 5:150-159.

6. Owens S, Rayner T, Bina O: New agendas for appraisal: reflections on theory. Pract Res Environ Plan A 2004, 36:1943-1959.

7. Adelle $\mathrm{C}$, Jordan A, Turnpenny $\mathrm{J}$ : Proceeding in parallel or drifting apart? A systematic review of policy appraisal research and practices. Environ Plan C Govern Policy 2012, 30:401-415.

8. Waterton C: From field to fantasy: classifying nature, constructing Europe. Soc Stud Sci 2002, 32:177-204.

9. Turnhout EM: A Critical Social Theory Perspective on Informational Governance. ET Info-gov Workshop 17 October 2013. 2013:. https:// http://www.wageningenur.nl/upload_mm/e/d/d/14805226-47d44dbd-bf79-56d5f991a972_IPOPIG-EstherTurnhout17-10-2013.pdf.

10. Sébastien L, Lehtonen M, Bauler T: Can indicators fill the gap between science and policy? An exploration of the (non) use and (non) influence of indicators in EU and UK policymaking. Nat Cult 2014, 9:316-343.

11. Mickwitz $\mathrm{P}$, Melanen $\mathrm{M}$ : The role of co-operation between

- $\quad$ academia and policymakers for the development and use of sustainability indicators - a case from the Finnish Kymenlaakso Region. J Clean Prod 2009, 17:1086-1100.

Illustrates the crucial importance of the indicator development process as a determinant of indicator use, and makes the case for collaborative indicator development.

12. Wibeck VJ, Johansson M, Larsson A, Öberg G: Communicative aspects of environmental management by objectives: examples from the Swedish context. Environ Manag 2006, 37:461-469.

13. Lehtonen M: The non-use and influence of UK Energy Sector Indicators. Ecol Indic 2013, 35:24-34.

14. Lyytimäki J, Tapio $P$, Varho V, Söderman T: The use, non-use and

- $\quad$ misuse of indicators in sustainability assessment and communication. Int J Sustain Dev World Ecol 2013, 20:385-393. Highlights the multiple indirect pathways through which sustainability indicators exert their influence - or fail to do so. Suggests a typology of different forms of sustainability indicator use based on the concepts of use, non-use, and misuse.

15. Weiss $\mathrm{CH}$ : The interface between evaluation and public policy. Evaluation 1999, 5:468-486.

16. Garb Y, Pulver S, Vandeveer SD: Scenarios in society, society in scenarios: toward a social scientific analysis of storylinedriven environmental modeling. Environ Res Lett 2008, 3:1-8.

17. Gallopin GC: Environmental and sustainability indicators and the concept of situational indicators: a systems approach. Environ Model Assess 1996, 1:101-117.

18. Turnhout EM: The effectiveness of boundary objects: the case -. of ecological indicators. Sci Publ Policy 2009, 36:403-412.

A key contribution to the analysis of indicators from the perspective of 'boundary object'.

19. Gudmundsson H: The policy use of environmental indicators learning from evaluation research. J Transdiscip Environ Stud 2003, 2:1-12.
20. Pintér L, Hardi P, Bartelmus P: Indicators of sustainable development: proposals for a way forward. Discussion Paper Prepared under a Consulting Agreement on behalf of the UN Division for Sustainable Development. UNDSD/EGM/ISD/2005/ CRP.2. IISD - International Institute for Sustainable Development; 2005.

21. Rosenström U, Lyytimäki J: The role of indicators in improving timeliness of international environmental reports. Eur Environ 2006, 16:32-44.

22. Mascarenhas A, Nunes LM, Ramos TB: Exploring the selfassessment of sustainability indicators by different stakeholders. Ecol Indic 2014, 39:75-83.

23. Jacobs R, Goddard M: How do performance indicators add up? An examination of composite indicators in public services. Publ Money Manag 2007, 27:103-110.

24. Jackson PM: Governance by numbers: what have we learned over the past 30 years? Publ Money Manag 2011, 31:13-26.

25. Sonntag V: Designing sustainability indicator frameworks for information flow: a case study of B-sustainable. Appl Res Qual Life 2010, 5:325-339.

26. Grupp H, Schubert T: Review and new evidence on composite innovation indicators for evaluating national performance. Res Policy 2010, 39:67-78.

27. Seaford C: The multiple uses of subjective well-being

- $\quad$ indicators. Soc Indic Res 2013, 114:29-43.

One of the earliest analyses of the potential of the emerging 'subjective' well-being indicators in governance. Outlines the potential roles of such indicators, identifies key barriers that may prevent indicators from playing their intended roles, and sketches two alternative scenarios for the future roles of well-being indicators.

28. Hezri AA: Connecting Sustainability Indicators To Policy Systems A Thesis Submitted for the Degree of Doctor of Philosophy. The Australian National University; 2006.

29. OECD: Environmental Indicators: A Preliminary Set. Paris: OECD; 1991.

30. Hood C: Public service management by numbers: why does it

- $\quad$ vary? Where has it come from? What are the gaps and the puzzles?. Publ Money Manag 2007, 27:95-102.

A concise survey of the state of the art in research analysing indicators from the perspective of 'management by numbers'.

31. Le Galès P: Rencontre avec Patrick Le Galès: Management public, le laboratoire britannique. Sci Hum 2011, 7:8.

32. Sébastien L, Bauler T: Use and influence of composite indicators for sustainable development at the EU-level. Ecol Indic 2013, 35:3-12.

33. Stiglitz JE, Sen A, Fitoussi J-P: Mismeasuring Our Lives. Why GDP

- $\quad$ Doesn't Add Up. The Report by the Commission on the Measurement of Economic Performance and Social Progress. New York and London: New Press; 2010.

Politically influential report of the so-called Stiglitz commission, which brought the work on alternative indicators of progress and well-being to the political agenda, and public consciousness.

34. Turcu C: Re-thinking sustainability indicators: local perspectives of urban sustainability. J Environ Plan Manag 2013, 56:695-719.

35. Argyris C, Schön D: Organisational Learning: A Theory of Action Perspective. Reading, MA: Addison Wesley; 1978.

36. Innes JE: Information in communicative planning. J Am Plan Assoc 1998, 64:52-63.

37. Ortega-Cerdà M: Sustainability Indicators as Discursive Elements. 6th International Conference of the European Society for Ecological Economics; Lisbon, 14-17 June: 2005. https://www. academia.edu/7045735/ SUSTAINABILITY_INDICATORS_AS_DISCURSIVE_ELEMENTS (accessed 3 June 2015).

38. Vedung E: Public Policy and Program Evaluation. New Brunswick NJ: Transaction Publishers; 1997. 
39. Hezri AA, Dovers SR: Sustainability indicators, policy and governance: issues for ecological economics. Ecol Econ 2006, 60:86-99.

40. Patton MQ: Utilization-focused Evaluation: The New Century Text. edn 3. Thousand Oaks, CA: SAGE; 1997.

41. Rapport DJ, Hildén M: An evolving role for ecological indicators: from documenting ecological conditions to monitoring drivers and policy responses. Ecol Indic 2013, 28:10-15.

42. Parris TM, Kates RW: Characterizing and measuring sustainable development. Ann Rev Environ Resour 2003, 28:1-28.

43. Bell S, Morse S: Measuring Sustainability. Learning From Doing. -• London: Earthscan; 2003.

A seminal work to the problems and possibilities associated with the use and development of sustainability indicators.

44. Henry GT, Mark MM: Beyond use: understanding evaluation's influence on attitudes and actions. Am J Eval 2003, 24:293-314.

45. Zittoun P: Indicateurs et cartographie dynamique du bruit, un instrument de reconfiguration des politiques publiques? Développement durable et territoires, Dossier 8: Méthodologies et pratiques territoriales de l'évaluation en matiere de développement durable (on line since 13th December 2006). 2006.

46. Lascoumes $P$, Le Galès $P$ (Eds): Gouverner par les instruments. - Paris: Les Presses de Science Po; 2005.

A seminal French-language publication examining indicators from a systemic perspective of 'governance by numbers'.

47. Star SL: This is not a boundary object: reflections on the origin -• of a concept. Sci Technol Hum Values 2010, 35:601-617. An update of the state of the art of scholarship applying the notion of 'boundary object', written by the one of the two authors that originally launched the concept. Describes the three essential characteristics of boundary objects and provides examples in order to rectify common misunderstandings.

48. Jasanoff S: Contested boundaries in policy-relevant science. Soc Stud Sci 1987, 17:195-230.

49. Bauler T: An analytical framework to discuss the usability of -• (environmental) indicators for policy. Ecol Indic 2012, 17:38-45 Underlines the importance of institutional embeddedness as a crucial determinant of the success of indicators as governance tools, and elaborates on the role of indicators in reflexive governance.
50. Bailey M, Bush S, Miller A, Kochen M: The business case for enhanced traceability: how information can transform seafood governance in the Global South. Curr Opin Environ Sustain Spec Issue Inf Govern Sustain 2015. [in this issue].

51. Jany-Catrice F: La longue marche vers de nouveaux indicateurs sur les territoires. Revue Savoir/Agir 2011, 11:93-101.

52. Cobb CW, Rixford C: Lessons Learned From the History of Social Indicators. San Francisco: Redefining Progress; 1998.

53. Pagani F: Peer Review: An OECD Tool For Co-operation and Change. Paris: OECD; 2003.

54. Morse S: Developing sustainability indicators and indices. Sustain Dev 2015 http://dx.doi.org/10.1002/sd.1575.

55. Bell S, Morse S: An analysis of the factors influencing the use of indicators in the European Union. Local Environ Int J Justice Sustain 2011, 16:281-302.

56. Efroymson RA, Dale VH, Kline KL, Mcbride AC, Bielicki JM, Smith RL, Parish ES, Schweizer PE, Shaw DM: Environmental indicators of biofuel sustainability: what about context? Environ Manag 2013, 51:291-306.

57. Newig J, Voss J-P, Monstadt J (Eds): Governance for Sustainable Development: Coping with Ambivalence, Uncertainty and Distributed Power. UK: Routledge, Oxon; 2008.

58. Rafols I, Ciarli T, Van Zwanenberg P, Stirling A: Towards Indicators for 'Opening Up' Science and Technology Policy. Presentation at the conference: Internet, Politics, Policy 2012: Big Data, Big Challenges?. 2012.

59. Srebotnjak T: The role of environmental statisticians in environmental policy: the case of performance measurement. Environ Sci Policy 2007, 10:405-418.

60. Rametsteiner E, Pülzl H, Alkan-Olsson J, Frederiksen P:

- Sustainability indicator development - science or political negotiation? Ecol Econ 2011, 11:61-70.

Describes the development of sustainability indicators as a process of both scientific 'knowledge production' and of political 'norm creation', and calls for greater attention to the latter as the currently underrated but essential part of indicator development.

61. Pielke R Jr: The Honest Broker: Making Sense of Science in Policy and Politics. Cambridge: Cambridge University Press; 2007. 